\title{
Electrophysiological actions of somatostatin on the atrioventricular junction in sinus rhythm and reentry tachycardia
}

\author{
STUART C WEBB, DENNIS M KRIKLER, W GORDON HENDRY, \\ THOMAS E ADRIAN, STEPHEN R BLOOM
}

From the Department of Medicine, Royal Postgraduate Medical School, London

SUMMARY Because somatostatin, a neuroregulatory peptide, is found in abundance in the atria and atrioventricular node, its electrophysiological and antiarrhythmic properties were compared with those of verapamil in ten patients with paroxysmal atrioventricular tachycardia. During sinus rhythm, intravenous somatostatin slowed the heart rate whereas verapamil increased it. Though both agents prolonged atrioventricular conduction time and refractoriness, verapamil was more potent. They were equally effective at terminating reentry atrioventricular tachycardia, restoring sinus rhythm in six of seven patients. Whereas verapamil consistently blocked conduction in the atrioventricular node, somatostatin usually induced ventricular extrasystoles at the time of conversion. Somatostatin may have physiological importance in the neurohumoral control of cardiac impulse formation and conduction.

Somatostatin and related peptides have been identified in many tissues from a wide range of species including man. ${ }^{12}$ Within the central nervous system, somatostatin functions as a neurohumoral agent and participates in neurotransmission. ${ }^{3}$ In other organs it inhibits endocrine and exocrine secretions and depresses absorption from the small bowel as well as slowing splanchnic blood flow. ${ }^{4}$ In addition, somatostatin is present in the normal heart $^{5}$ and has various effects on the cardiovascular system. These include bradycardia in guinea pigs ${ }^{6}$ and bradycardia and a transient increase in systemic arterial pressure in healthy human volunteers ${ }^{7}$ given intravenous somatostatin. Atrioventricular nodal function is depressed and termination of paroxysmal supraventricular tachycardia has been seen. ${ }^{89}$

Somatostatin is particularly abundant in the atria and atrioventricular node. ${ }^{5}$ Though little is known about the mechanism of action of endogenous or exogenous somatostatin on cardiac tissue, it exerts negative inotropic effects on guinea pig atria that can be reversed by increasing the calcium ion concen-

Requests for reprints to Dr Dennis M Krikler, Cardiovascular Division, Department of Medicine, Hammersmith Hospital, Du Cane Road, London W120HS.

Accepted for publication 13 May 1986 tration of the perfusing medium ${ }^{10}$; this has raised the question whether somatostatin may act as a calcium antagonist.

To explore the electrophysiological role of somatostatin, and also to assess its possible therapeutic usefulness, we have compared its effects with those of verapamil in a group of patients undergoing investigation of paroxysmal supraventricular tachycardia. We determined the effects of both drugs on standard measurements of intracardiac conduction velocity and refractoriness during sinus rhythm, and also examined their antiarrhythmic properties in those patients in whom reentry atrioventricular tachycardia could reproducibly be induced.

\section{Patients and methods}

Ten patients underwent routine intracardiac electrophysiological investigation of paroxysmal supraventricular tachycardia. After premedication with oral diazepam, four multipolar recording electrode wires were introduced percutaneously via the right femoral and left subclavian veins to permit recording and stimulation from high right atrium, coronary sinus, bundle of $\mathrm{His,}$ and right ventricular apex. ${ }^{11}$ Table 1 shows the clinical details of the 
Table 1 Clinical details of study patients

\begin{tabular}{|c|c|c|c|}
\hline Patient & Age (yr) & Sex & Diagnosis \\
\hline $\begin{array}{r}1 \\
2 \\
3 \\
4 \\
5 \\
6 \\
7 \\
8 \\
9 \\
10\end{array}$ & $\begin{array}{l}37 \\
34 \\
51 \\
19 \\
40 \\
50 \\
38 \\
53 \\
32 \\
63\end{array}$ & $\begin{array}{l}\mathbf{M} \\
\mathbf{M} \\
\mathbf{F} \\
\mathbf{M} \\
\mathbf{M} \\
\mathbf{M} \\
\mathbf{F} \\
\mathbf{M} \\
\mathbf{M} \\
\mathbf{F}\end{array}$ & 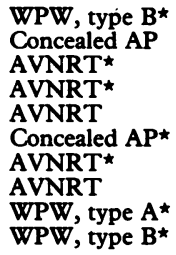 \\
\hline
\end{tabular}

WPW, Wolff-Parkinson-White syndrome; AVNRT, atrioventricular nodal reentry tachycardia; AP, accessory pathway.

$\star$ Patients in whom tack 'cardia was sustained.

patients. All had reentry tachycardia which was associated with an accessory atrioventricular pathway in five and due to presumed dual atrioventricular nodal pathways in the remainder.

When the diagnostic investigation had been completed, baseline measurements were made of sinus cycle length, intracardiac conduction times, and the effective refractory periods of the right atrium, right ventricle and, where possible, the atrioventricular node. An attempt was then made to initiate sustained supraventricular tachycardia by programmed electrical stimulation. An intravenous infusion of somatostatin (Modustatine, Sanofi) at $12.5 \mu \mathrm{g} / \mathrm{min}$ was started in all patients. In those in whom tachycardia had been initiated, serial measurements of cycle length and regional conduction times $\left(A^{\prime} H\right.$, $\mathrm{HV}$, and $\mathrm{VA}^{\prime}$ intervals) were made until sinus rhythm was restored or until 10 minutes had elapsed. If the tachycardia persisted, it was terminated by programmed electrical stimulation. Measurements of resting sinus cycle length and other electrophysiological variables were repeated between the tenth and fifteenth minute of somatostatin infusion, at which stage the drug was discontinued. When all variables had returned to control values a bolus intravenous injection of verapamil $(0.15 \mathrm{mg} / \mathrm{kg})$ was given and the same variables were measured for comparison.

Samples of venous blood were withdrawn before the infusion of somatostatin was started and 5, 10 , and 20 minutes afterwards. They were centrifuged immediately and the supernatant plasma was stored at $-40^{\circ} \mathrm{C}$. Concentrations of somatostatin, motilin, and pancreatic polypeptide were determined by standard assay techniques. ${ }^{12}$ All results were expressed as the mean (SEM) and we used Student's $t$ test for comparison.

Informed written consent was obtained from all patients before the study. The experimental protocol had been approved by the ethics committee of the Royal Postgraduate Medical School.

\section{Results}

Somatostatin reduced the heart rate in sinus rhythm, prolonging the cycle length by 54 (37) ms (table 2), whereas verapamil shortened the sinus cycle length by $44(21) \mathrm{ms} \quad(\mathrm{p}<0.02$ between groups). Both drugs tended to slow atrioventricular conduction, but somatostatin prolonged the $\mathrm{AH}$ interval $(9(3) \mathrm{ms})$ less than verapamil $(40(8) \mathrm{ms})$ $(p<0.005)$. Assessment of other indices of atrioventricular nodal function was limited in some patients by atrial refractoriness, persistence of anterograde conduction along the accessory pathway, or the initiation of reentry tachycardia. In five patients, however, the atrioventricular nodal anterograde refractory period was prolonged by 35 (8) $\mathrm{ms}$ during somatostatin infusion and by $83(38) \mathrm{ms}$ after verapamil (NS). The cycle length at which type I second degree atrioventricular block developed during incremental atrial pacing, determined in six patients, was also prolonged to a greater extent with verapamil than with somatostatin $(150(44) \mathrm{ms}$ vs 43 (11) ms, p < 0.05). Neither agent caused significant changes in His-Purkinje conduction (HV interval) or ventricular effective refractory period (table 2). The atrial refractory period was prolonged by both somatostatin and verapamil, but only with somatostatin was this change significant.

Sustained reentry tachycardia could be repeatedly induced in seven of the ten patients in this study. When somatostatin was given during tachycardia, conversion to sinus rhythm occurred in six patients after a mean interval of 277 (90) s (table 3). Whereas in one instance the tachycardia was terminated by block of anterograde conduction in the atrioventricular node, in the remaining five conversion was associated with the occurrence of ventricular extrasystoles (fig 1). The maximum number of consecutive extrasystoles was three and their configuration indicated sites of origin that were left ventricular (two patients), right ventricular (one patient), or indeterminate (two patients). Resumption of sinus rhythm was prompt, though in one case this was prereded by two supraventricular extrasystoles (fig 1). During tachycardia, somatostatin caused modest slowing of heart rate attributable to lengthening of atrioventricular nodal conduction time. When recordings made immediately before termination were compared with those made before somatostatin infusion, tachycardia cycle length and $A^{\prime} H$ interval were seen to be prolonged by 30 (11) and 25 (11) ms respectively. $\mathrm{HV}$ and $\mathrm{VA}^{\prime}$ intervals were unchanged.

Verapamil also terminated reentry tachycardia in six of seven patients, but, in contrast with the effects of somatostatin, this occurred soon (33(4) ms after 
Table 2 Comparison of the changes in electrophysiological measurements made after a 10 min infusion of somatostatin $(12.5 \mu \mathrm{g} / \mathrm{min})$ with those recorded $10 \mathrm{~min}$ after a bolus injection of verapamil $(0.15 \mathrm{mg} / \mathrm{kg})$

\begin{tabular}{|c|c|c|c|c|c|c|c|}
\hline & \multicolumn{3}{|c|}{ Somatostatin } & \multicolumn{3}{|c|}{ Verapamil } & \multirow{2}{*}{$\begin{array}{l}\text { Comparison of } \\
\text { drug effects } \\
(p)\end{array}$} \\
\hline & Pre & Post & Change (p) & Pre & Post & Change (p) & \\
\hline $\begin{array}{l}\text { SCL } \\
\text { AH interval } \\
\text { HV interval } \\
\text { Atrial ERP } \\
\text { Ventricular ERP } \\
\text { AVN ERP } \\
\text { AVN WCL }\end{array}$ & $\begin{array}{c}722(30) \\
79(7) \\
43(4) \\
203(6) \\
241(4) \\
277(8) \\
338(10)\end{array}$ & $\begin{array}{c}776(33) \\
88(7) \\
45(3) \\
220(9) \\
242(4) \\
312(17) \\
381(14)\end{array}$ & $\begin{array}{l}\text { NS } \\
<0.005 \\
\text { NS } \\
<005 \\
\text { NS } \\
<0.05 \\
<0.02\end{array}$ & $\begin{array}{c}731(36) \\
81(6) \\
45(3) \\
205(7) \\
242(6) \\
282(12) \\
327(17)\end{array}$ & $\begin{array}{c}687(20) \\
121(12) \\
46(3) \\
213(7) \\
239(11) \\
365(46) \\
477(53)\end{array}$ & $\begin{array}{l}<0.05 \\
<0.001 \\
\text { NS } \\
\text { NS } \\
\text { NS } \\
<0.05 \\
<0.02\end{array}$ & $\begin{array}{l}<0.02 \\
<0.005 \\
\text { NS } \\
\text { NS } \\
\text { NS } \\
\text { NS } \\
<0.05\end{array}$ \\
\hline
\end{tabular}

SCL, sinus cycle length; ERP effective refractory period; AVN, atrioventricular node; WCL, atrial paced cycle length at which type I second degree atrioventricular block occurred. All values in ms, expressed as mean (SEM).

Table 3 Timing and circumstances of termination of reentry atrioventricular tachycardia observed during somatostatin infusion and after bolus injection of verapamil

\begin{tabular}{|c|c|c|c|c|c|c|}
\hline \multirow[b]{2}{*}{ Patient } & \multicolumn{3}{|l|}{ Somatostatin } & \multicolumn{3}{|l|}{ Verapamil } \\
\hline & Delay (s) & Mode & $\triangle C L(m s)$ & Delay (s) & Mode & $\triangle C L(m s)$ \\
\hline $\begin{array}{r}1 \\
3 \\
4 \\
6 \\
7 \\
9 \\
10\end{array}$ & $\begin{array}{l}240 \\
70 \\
\text { No termination } \\
520 \\
540 \\
64 \\
210\end{array}$ & $\begin{array}{l}\text { VES (2) } \\
\text { AVB } \\
\text { VES (3) } \\
\text { VES (3) } \\
\text { VES (1) } \\
\text { VES (1) }\end{array}$ & $\begin{array}{r}+30 \\
+90 \\
(+10) \\
0 \\
+15 \\
+30 \\
+30\end{array}$ & $\begin{array}{l}24 \\
\text { No termination } \\
40 \\
45 \\
28 \\
31 \\
34\end{array}$ & $\begin{array}{l}\text { AVB } \\
\text { AVB } \\
\text { AVB } \\
\text { AVB } \\
\text { AVB } \\
\text { AVB }\end{array}$ & $\begin{array}{l}+110 \\
(+25) \\
+100 \\
+190 \\
+65 \\
+90 \\
+80\end{array}$ \\
\hline
\end{tabular}

$\triangle \mathrm{CL}$, prolongation of tachycardia cycle length before termination (or after $10 \mathrm{~min}$ ); AVB, atrioventricular block; VES, ventricular extrasystoles.

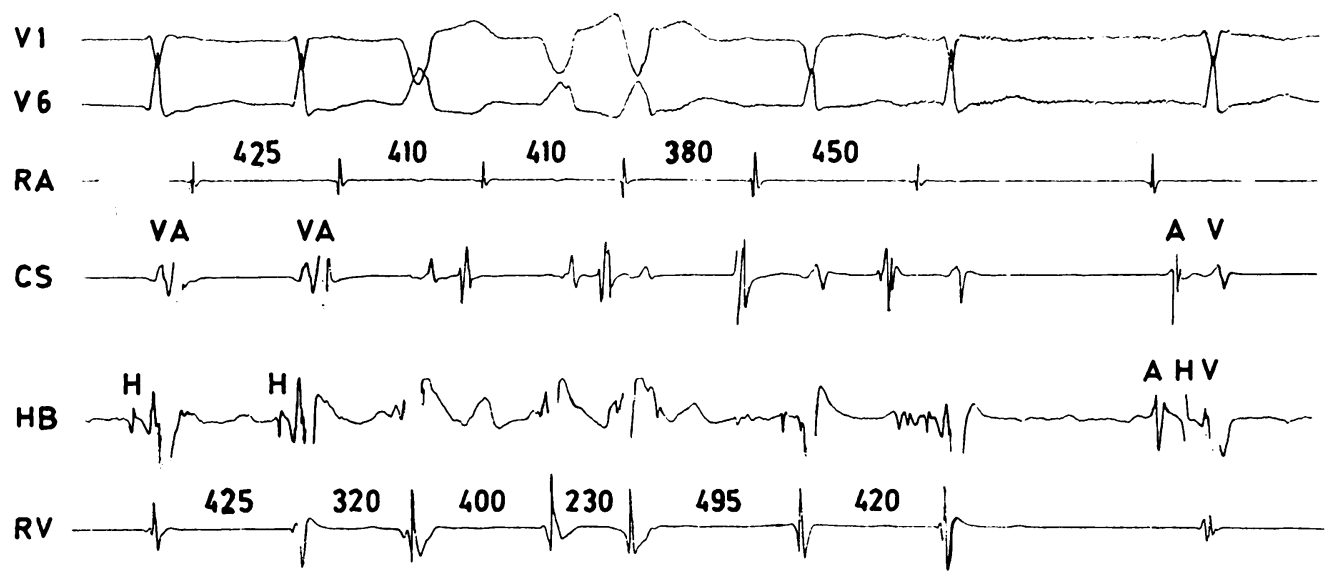

Fig 1 Electrocardiograms (V1 and V6) and simultaneous intracardiac electrograms showing termination of atrioventricular nodal reentry tachycardia nine minutes after intravenous infusion of somatostatin was started (patient 6). Three consecutive ventricular extrasystoles followed by two atrial extrasystoles were recorded before restoration of sinus rhythm. (Intervals shown in ms.) $R A$, high right atrium; CS, coronary sinus; HB, bundle of His; $R V$, right ventricular apex. 
administration) and was in all cases attributable to anterograde atrioventricular nodal block (fig 2). Termination was preceded by conspicuous reduction of the tachycardia rate and slowing of atrioventricular nodal conduction, the tachycardia cycle length and $\mathrm{A}^{\prime} \mathrm{H}$ interval being prolonged by 91 (19) $\mathrm{ms}$ and 86 (16) ms respectively (table 3 ). Both these changes were significantly greater than those observed with somatostatin ( $p<0.05$ between groups for each variable).

Verapamil was well tolerated, with no side effects. Somatostatin, however, caused mild to moderate nausea in four patients, one of whom also experienced abdominal cramps. During infusion a high plasma concentration of somatostatin was maintained, and the concentration recorded $10 \mathrm{~min}$ after the end of infusion indicated a plasma half life of between two and three minutes: these changes were accompanied by progressive reduction in the concentration of motilin and pancreatic polypeptide (fig 3).

\section{Discussion}

Studies on the effects of somatostatin on the cardiovascular system in animal preparations have yielded conflicting data. Somatostatin shows negative inotropic and chronotropic properties when applied to the atria of both the toad Bufo marinus ${ }^{13}$ and the guinea pig ${ }^{10}$ but has no effect in similar experiments on hearts obtained from the frog Rana esculenta, ${ }^{14}$ rat, or rabbit. ${ }^{10}$ Such species variation may be reflected in the uniformly low somatostatin content of cardiac tissues in the rat in contrast with the high concentrations found in the atria of the guinea pig. ${ }^{5}$ There is a similar correlation in man between the cardiac effects of somatostatin and its tissue distribution. Intravenous infusion of somatostatin slows the sinus rate and depresses atrioventricular conduction, and, as judged by immunoreactivity, this peptide is abundant in human atrial and atrioventricular nodal tissue. ${ }^{5}$

The inhibitory properties of somatostatin on pancreatic islet $\beta$ cells are reversed by exposure to an ionophore that increases calcium permeability. ${ }^{15}$ The negative inotropic effects of somatostatin on guinea pig atria can be potentiated by reducing the extracellular calcium concentration and antagonised by increasing it. ${ }^{10}$ Because such observations had raised the possibility that somatostatin functions as a calcium antagonist ${ }^{5810}$ the design of the present study included a test of this hypothesis: the actions of somatostatin were compared with those of verapamil.

During sinus rhythm, both somatostatin and verapamil slowed atrioventricular nodal conduction and prolonged atrioventricular nodal refractoriness; verapamil was consistently more potent. Sinus cycle

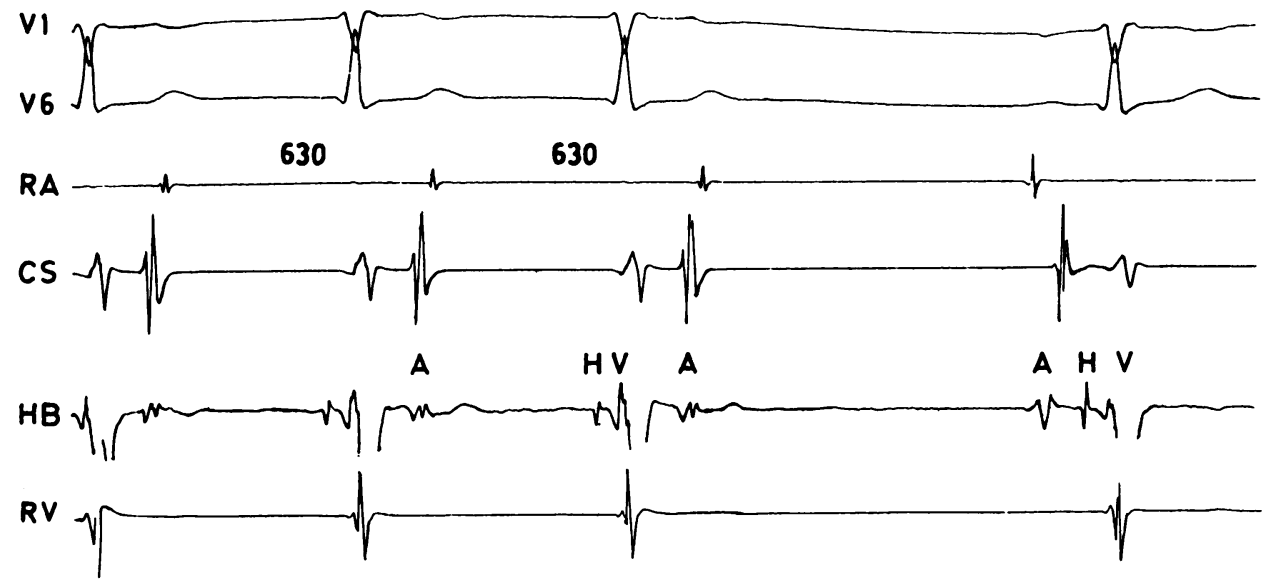

Fig 2 Electrocardiograms (V1 and V6) and simultaneous intracardiac electrograms showing termination of atrioventricular nodal reentry tachycardia occurring $45 \mathrm{~s}$ after bolus injection of verapamil (patient 6 ). Progressive prolongation of the $A^{\prime} H$ interval (from 270 to $435 \mathrm{~ms}$ ) preceded the development of anterograde block in the atrioventricular node and rapid restoration of sinus rhythm. Abbreviations as in fig 1 . 


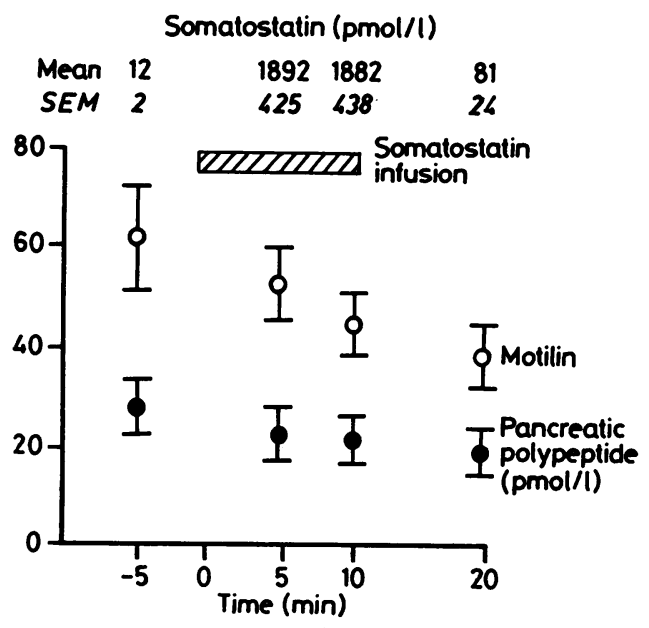

Fig 3 Progressive reduction in the plasma concentrations of pancreatic polypeptide and motilin during somatostatin infusion. Note the rapid decline in the concentration of somatostatin after the infusion had been discontinued.

length, however, was prolonged by somatostatin but shortened by verapamil. This does not necessarily imply that these agents have qualitatively different effects on the sinus node-the tachycardia caused by verapamil is due to a reflex increase in sympathetic tone secondary to vasodilatation. ${ }^{16}$ Hypotension does not occur during intravenous administration of somatostatin; indeed a transient increase in blood pressure has sometimes been seen in clinical studies, suggesting that it may cause vasoconstriction.? Although somatostatin cannot be regarded as a conventional calcium antagonist, ${ }^{17}$ its effect on the cellular movement of $\mathrm{Ca}^{++}$remains to be assessed. Intracellular recordings and voltage-clamp studies indicate that both adenosine and acetylcholine increase the $\mathrm{K}^{+}$permeability of atrial myocytes, ${ }^{18} 19$ thereby abbreviating the action potential and reducing $\mathrm{Ca}^{++}$influx. ${ }^{20}$ Some of the electrophysiological properties of these compounds closely resemble those of somatostatin, ${ }^{21}$ raising the possibility that they have a similar cellular mechanism of action.

During reentry atrioventricular tachycardia, the antiarrhythmic activity of verapamil was mediated by atrioventricular nodal depression. ${ }^{22}$ The relatively weaker negative dromotropic effects of somatostatin were usually insufficient to interrupt the reentry circuit, and in most cases termination was accompanied by ventricular extrasystoles. Though it is possible that this electrical activity was spontaneous, extrasystoles were not present in these patients under resting conditions, and were not observed at any time during the episodes of reentry tachycardia that were terminated by verapamil.
Both atrial and ventricular extrasystoles may be seen when supraventricular tachycardia is terminated by vagotonic manoeuvres ${ }^{23}$ or by vagomimetic agents like methacholine. ${ }^{24}$ This electrical activity is usually observed in the period immediately after the end of tachycardia, and may thus originate from an automatic focus that has a lower intrinsic rate than normal pacemaker tissue but that is less sensitive to the effects of vagal stimulation. ${ }^{25}$ This mechanism cannot, however, account for extrasystoles arising during the course of supraventricular tachycardia, as was observed with somatostatin. The nature of this effect of somatostatin remains obscure. In the absence of any detectable changes in either ventricular effective refractory period or intraventricular conduction velocity, the possibility that somatostatin initiates triggered activity needs to be considered.

Though somatostatin was as effective as verapamil in restoring sinus rhythm, verapamil ensured more rapid termination, protected against early reinitiation, and produced fewer constitutional side effects. The dosage and mode of administration of somatostatin were different from those in previous reports when frequently repeated small bolus doses or continuous infusion at $25 \mu \mathrm{g} / \mathrm{min}$ were used. ${ }^{89} \mathrm{In}$ these studies, restoration of sinus rhythm took up to $15 \mathrm{~min}$, which is much longer than the established half life of somatostatin. ${ }^{26}$ Though no side effects were noted in patients receiving somatostatin at $25 \mu \mathrm{g} / \mathrm{min}$, apart from nausea, ${ }^{8}$ we found that two patients vomited at this infusion rate and we therefore reduced the dose to $12.5 \mu \mathrm{g} / \mathrm{min}$. This failed to prevent nausea in four subjects or abdominal discomfort in one. The infusion, however, produced a $>100$ fold increase in the plasma somatostatin concentration, and the progressive reduction in the circulating concentrations of motilin and pancreatic polypeptide indicated that a therapeutically effective concentration of somatostatin had been achieved. ${ }^{27}$

In conjunction with the observation that somatostatin is present in cardiac tissue, ${ }^{5}$ the demonstration that this peptide possesses electrophysiological properties suggests that it may have a functional role within the cardiovascular system. The effects of exogenous somatostatin on the sinus and atrioventricular nodes resemble those of vagal stimulation. The localisation of somatostatin in postganglionic intracardiac neurones in the toad ${ }^{13}$ and the efficacy of atropine in antagonising its chronotropic and dromotropic effects in $\operatorname{man}^{8}$ provide further evidence that somatostatin may participate in the mediation of cardiac parasympathetic tone. Somatostatin is known to function as a neuroregulator and cotransmitter at other sites in the autonomic and central nervous systems. ${ }^{2829}$ Fur- 
ther studies are required to establish the role of this peptide at cardiac neuroeffector junctions. Immunocytochemical examination of human sinus and atrioventricular nodal tissue, detailed assessment of the effects of somatostatin on isolated heart preparations, and clinical tests with coadministration of autonomic agonists and antagonists are in progress.

We thank Dr J-P Gagnol, Sanofi Laboratories, Montpellier, France, for supplying the somatostatin.

\section{References}

1 Vale W, Ling G, River J, et al. Anatomic and phylogenetic distribution of somatostatin. Metabolism 1976;25(suppl 1):1491-4.

2 Polak J, Pearse AGE, Crimelius L, Bloom S, Arimura A. Growth-hormone release-inhibiting hormone in gastrointestinal and pancreatic D cells. Lancet 1975;i:1220-2.

3 Reichlin S. Somatostatin. N Engl $\mathcal{f}$ Med 1983; 309:1495-501.

4 Anonymous. Somatostatin: hormonal and therapeutic roles. Lancet 1985;ii:77-8.

5 Day SM, Gu J, Polak JM, Bloom SR. Somatostatin in the human heart and comparison with guinea pig and rat heart. Br Heart $\mathcal{F}$ 1985;53:153-7.

6 Rioux F, Kérouac R, St-Pierre S. Somatostatin: interaction with the sympathetic nervous system in guinea pigs. Neuropeptides 1981;1:319-27.

7 Chernish SM, Miller RE, Rosenak BD, Brunelle RD. The effect of D-val ${ }^{1}, \mathrm{D}$-Tryp ${ }^{8}$, somatostatin on the hematopoetic, cardiovascular systems and gastrointestinal tract [Abstract]. Gastroenterology 1979;76: 1113.

8 Sandric S, Santarelli P, Uccioli L, et al. Electrophysiologic effects of somatostatin in man [Abstract]. f Am Coll Cardiol 1984;3(suppl 2):55.

9 Greco AV, Ghirlanda G, Barone C, et al. Somatostatin in paroxysmal supraventricular and junctional tachycardia. Br Med fु 1984;288:28.

10 Quirion R, Regoli D, Rioux F, St-Pierre S. An analysis of the negative inotropic action of somatostatin. $\mathrm{Br} \mathcal{F}$ Pharmacol 1979;66:251-7.

11 Curry PVL. Fundamentals of arrhythmias: modern methods of investigation. In: Krikler DM, Goodwin JF, eds. Cardiac arrhythmias: the modern electrophysiological approach. London: WB Saunders, 1975:39-80.

12 Adrian TE. Radioimmunoassay. In: Bloom SR, Long RG, eds. Radioimmunoassay of gut regulatory peptides. London: WB Saunders, 1982:3-10.

13 Campbell G, Gibbins IL, Morris JL, et al. Somato- statin is contained in and released from cholinergic nerves in the heart of the toad Bufo marinus. Neuroscience 1982;7:2013-23.

14 Stene-Larsen G, Helle KB. Inotropic and chronotropic effects of neurotensin in the rat atrium and of physalaemin in the auricles of $R$ esculenta. Comp Biochem Physiol [C] 1979;64C:279-83.

15 Fujimoto WY, Ensink JW. Somatostatin inhibition of insulin and glucagon secretion in rat islet culture: reversal by ionophore A23187. Endocrinology 1976;98:259-61.

16 Breithardt G, Seipel L, Weibringhaus E, Loogen F. Effects of verapamil on sinus node function in man. Eur $\mathcal{f}$ Cardiol 1978;8:379-94.

17 Fleckenstein A, Tritthart A, Fleckenstein B, Herbst A, Grün G. Eine neue Gruppe kompetitiver $\mathrm{Ca}^{++}$ Antagonisten (Iproveratril, D600, Prenylamin) mit starken Hemeffekten auf die elektromekanische Koppelung in Warmblüter-Myokard. Pflügers Arch 1969;307:R25.

18 Belardinelli L, Isenberg G. Isolated atrial myocytes: adenosine and acetylcholine increase potassium conductance. Am F Physiol 1983;244:H734-7.

19 Ten Eick R, Nawrath H, McDonald TF, Trautwein W. On the mechanism of the negative inotropic effect of acetylcholine. Pflügers Arch 1976;361:207-13.

20 Grossman A, Furchgott RF. The effects of various drugs on calcium exchange in the isolated guinea pig left auricle. F Pharmacol Exp Ther 1964;145:162-72.

21 Drury AN, Szent-Györgyi A. The physiological activity of adenine compounds with especial reference to their activity upon the mammalian heart. $\mathcal{F}$ Physiol 1926;68:213-37.

22 Krikler DM, Spurrell RAJ. Verapamil in the treatment of paroxysmal reentrant supraventricular tachycardia. Postgrad Med f 1974;50:447-53.

23 Scherf D, Schott A. Extrasystoles and allied arrhythmias. London: William Heinemann Medical Books, 1973:496-506.

24 Bellet S. Clinical disorders of the heart beat. Philadelphia: Lea and Febiger, 1971:1114-24.

25 Cranefield PF. The conduction of the cardiac impulse. New York: Futura Publishing Company, 1975: 267-313.

26 Vale W, Rivier C, Brazeau P, Guillemin R. Effects of somatostatin on the secretion of thyrotropin and prolactin. Endocrinology 1974;95:968-77.

27 Schusdziarra V. Somatostatin-a regulatory modulator connecting nutrient entry and metabolism. Horm Metab Res 1980;12:563-77.

28 Burnstock G. Nervous control of smooth muscle by transmitters, cotransmitters and modulators. Experientia 1985;41:869-74.

29 Høkfelt T, Johansson O, Ljungdahl A, Lundberg JM, Schultzberg $M$. Peptidergic neurones. Nature 1980;284:515-21. 